\title{
EL MARCO ANALÍTICO DE LA PROTECCIÓN SOCIAL EN HONDURAS
}

ISSN 2219-6722

ISSNE 2222-2707

\author{
MARGARITA DÍAZ, Instituto de Investigaciones Económicas y Sociales (IIES) \\ Universidad Nacional Autónoma de Honduras(UNAH) \\ mdiaz@iies-unah.org \\ OZIEL FERNÁNDEZ, Doctorado en Gestión del Desarrollo \\ Universidad Nacional Autónoma de Honduras(UNAH) \\ ozi.economic@gmail.com \\ CESAR HERNÁNDEZ, Facultad de Ciencias Económicas y Sociales \\ Universidad Nacional Autónoma de Honduras(UNAH) \\ cesaryanuario@hotmail.com
}

\section{RESUMEN}

El marco analítico de la protección social y sus relaciones económicas tiene dos ángulos de referencia: Uno, el contexto de la vulnerabilidad económica y de la subsistencia y su vinculación con diferentes condiciones socio-demográficas de la población hondureña.

Dos, el gasto sectorial -salud, educación y de la protección social- permitiendo dimensionar los distintos niveles de riesgos y privaciones de los grupos de población vinculados al empleo, el desempleo, las discapacidades, las jubilaciones y el envejecimiento de la población.

El análisis se estableció desde el marco de: i.- Los niveles de pobreza, ii.- El panorama del mercado laboral y iii.- Las asignaciones presupuestarias del gasto público sectorial -salud, educación y en especial las de seguridad social- mostrándose la demanda de servicios públicos y de bienestar social. El marco analítico del gasto social y la conformación de la protección social, son dimensionados en relación con otros factores demográficos y socioeconómicos.

Palabras clave: Pobreza, mercado laboral, gasto social, protección social 


\title{
THE ANALYTICAL FRAMEWORK OF SOCIAL PROTECTION IN HONDURAS
}

ISSN 2219-6722

ISSNE 2222-2707

\author{
MARGARITA DÍAZ, Instituto de Investigaciones Económicas y Sociales (IIES) \\ Universidad Nacional Autónoma de Honduras(UNAH) \\ mdiaz@iies-unah.org \\ OZIEL FERNÁNDEZ, Doctorado en Gestión del Desarrollo \\ Universidad Nacional Autónoma de Honduras(UNAH) \\ ozi.economic@gmail.com \\ CESAR HERNÁNDEZ, Facultad de Ciencias Económicas y Sociales \\ Universidad Nacional Autónoma de Honduras(UNAH) \\ cesaryanuario@hotmail.com
}

\begin{abstract}
The analytical framework of social protection and their economic relationships has two reference angles: one is the context of the economic and livelihood vulnerability and its relationship with different socio-demographic conditions of the Honduran population.

The other is the sectorial spending -health, education and social protection-, which allowed to measure the different levels of risk and deprivation of population groups linked to employment, unemployment, disability, retirement, and aging of the population.

The analysis was established from the framework of: i.- Poverty levels, ii.- The picture of the labor market, and iii.- The budgetary assignments of the sectorial public expenditure -health, education and especially social security- showing a demand for public services and social welfare. The analytical framework of social spending and the establishment of social protection are dimensioned in relation to other demographic and socioeconomic factors.
\end{abstract}

Keywords: Labor market, social spending, social protection 


\section{I.- INTRODUCCIÓN}

El marco analítico de la protección social y sus relaciones demográficas y socio-económicas se planteó desde el contexto de la pobreza y del mercado laboral y su vinculación con diferentes condiciones socio-demográficas de la población hondureña. Lo que ha permitido dimensionar los distintos niveles de vulnerabilidad, de riesgos y privaciones de los grupos de población vinculados al empleo, el desempleo, la enfermedad, la maternidad, la crianza de los hijos, la viudez, las discapacidades y el envejecimiento de la población.

En este contexto se analizaron, por un lado, los aspectos más relevantes que describen la pobreza, mercado laboral y el gasto social y su cobertura en relación a la educación, lo social, la salud, las pensiones.

Los grupos de población que están fuera de la protección social son los pobres, desempleados, sub-empleados, trabajadores informales y los que viven en zonas rurales alejados de todos los servicios sociales; en Honduras, así como, en el resto de los países latinoamericanos 2 de cada 3 personas no tienen cobertura básica y de calidad de los riesgos sociales: enfermedad, pérdida de ingresos, desempleo, sobrevivencia, enfermedad, invalidez o vejez.

El análisis se estableció desde el marco de: i.- Los niveles de pobreza, ii.- El panorama del empleo y iii.- Las asignaciones presupuestarias del gasto público sectorial -salud, educación y en especial las de seguridad social- mostrándose la demanda de servicios públicos y de bienestar social, siendo este marco en el cual se presenta una serie de consideraciones anticipatorias. El marco analítico del gasto social y la conformación de la protección en el país, no puede ser presentado en relación con otros factores demográficos y socioeconómicos.

\section{II.- OBJETIVOS \\ Objetivo general}

Definir un marco de análisis sobre el mercado laboral, la pobreza y el gasto sectorial de manera de contextualizar la protección social y sus vinculaciones con lo económico, social y lo demográfico, permitiendo tener un referente para su análisis.

\section{Objetivos específicos}

1.- Analizar el panorama general del mercado laboral en Honduras, describiendo los principales indicadores sensibles.

2.- Determinar la tendencia de la pobreza y su incidencia en la población desde el 2001 a la fecha.

3.- Describir el contexto general del gasto en salud, educación, y en especial del gasto en protección social.

\section{III.- METODOLOGÍA}

Una revisión sobre las implicaciones que tiene el gasto y de protección social en un marco de referencia tiene dos niveles de análisis: i.- Un análisis conceptual, en el cual se ha vinculado factores importantes en las tendencias socio-económicas, ii.- Un análisis de las variables socio-económicas -el panorama de la realidad actual de la protección social y su vinculación con la población y su evolución. 
Se recurrió a la revisión de algunas fuentes de información alternas a las estadísticas nacionales, de manera de poder constatar la consistencia de las cifras y las coincidencias de las fuentes referidas. O porque algunas estadísticas no existen en las fuentes nacionales, pero si se encuentran en fuentes alternativas, como las generadas por CELADE, Banco Mundial y BID.

Por otro lado, los cálculos de indicadores fueron útiles para determinar los niveles de pobreza y del mercado laboral, y del gasto social.

Los criterios de clasificación de los indicadores son uno de los aspectos fundamentales para garantizar los resultados. Se tomaron en cuenta las estadísticas oficiales del Instituto Nacional de Estadísticas (INE) y otras fuentes de reconocida credibilidad regional.

\section{IV.- RESULTADOS}

\section{IV.1.-Caracterización general de la pobreza}

\section{IV.1.1.-Tendencia de la pobreza según categoría Extrema-Relativa y las áreas Urbano-Rural/}

\section{Pobreza por categoría extrema y relativa}

El total de hogares para el 2011 era de 1,718.338, de los cuales se estimó que el 61.9\% se encontraba en condiciones de pobreza, ya que sus ingresos se encontraron por debajo del costo de una canasta básica, la que se resume como un conjunto de bienes y servicios indispensables para que una persona cubra sus necesidades básicas a partir de su ingreso y de esa manera le ayuda a la subsistencia diaria. El 20.3\% de los hogares son pobres relativos y $41.6 \%$ son pobres extremos ${ }^{2}$. La pobreza para efectos de este análisis contextual fue referido al período de 1991-2011, y se sub-dividió en dos períodos de análisis (Ver Gráfico No.1).

\section{Período 1991-2001}

La pobreza total para 1991 registró un $74.8 \%$ con respecto al 2001 que fue de $63.7 \%$, descendiendo la pobreza total en 11.1 puntos porcentuales; en ese mismo sentido, la pobreza extrema pasó de 54.2\% para el 1991 a $44.2 \%$ para el 2001; por otro lado, la pobreza relativa paso de $20.6 \%$ en 1991 a $19.5 \%$ para el 2001. Lo que refleja que la pobreza extrema disminuyó $10 \%$ en el período y la pobreza relativa bajó apenas $1.1 \%$ en el mismo período.

\section{Período 2001-2011}

Al comparar la pobreza total en el período 2001 al 2011, se registraron un $63.7 \%$ y un $61.9 \%$ respectivamente, con apenas una disminución en ese período de un 1.8 punto porcentual. Para el mismo período, la pobreza extrema registro en 1991 un 44.2\% y para el 2011 un $41.6 \%$, lo que refleja que apenas disminuyo en un $2.6 \%$ en ese período. Por otro lado, la pobreza relativa para el año 2001 fue de un $19.5 \%$ y para el 2011 un $20.3 \%$, lo que significa que para este período la pobreza relativa creció 0.8 puntos porcentuales. Importante destacar es que se registró un índice de pobreza a nivel nacional en el 2007 en un 58.2\%, el porcentaje de pobreza más bajo en ese período de estudio. 
Al comparar estos dos períodos de análisis, en el primer período 1991-2001, la reducción de la pobreza fue significativa, indicando una mejoría de la calidad de vida de la población en general; en cambio, el segundo período 2001-2011, la situación no fue lo misma, la reducción de la pobreza no presento el mismo dinamismo, lo que significa en términos comparativos, los esfuerzos gubernamentales efectuados no fueron suficientes para lograr reducir la pobreza en este segundo período de análisis. Otros factores coyunturales de orden político, como el golpe de Estado en el 2009 afectaron negativamente las condiciones de estabilidad económica del país, lo que produjo a su vez un rechazo la comunidad internacional y recortes drásticos de proyectos y programas de desarrollo; por otro lado, el no reconocimiento del gobierno impuesto resultado del golpe de estado por un número considerable de países provocó cerrarle las puertas de credibilidad al país; la crisis económica internacional afectó al país directamente ante la limitación de acceso a fondos frescos para financiar la estructura económica y social.

Aún faltaron mejores y más esfuerzos por mejorar las condiciones de vida de la población, esto por la vía de incentivar el acceso a mejores trabajos para que la subsistencia de la población para lograr mejores condiciones de una vida digna.

Figura No. 1 Honduras: Pobreza en hogares a nivel nacional período 1991-2011

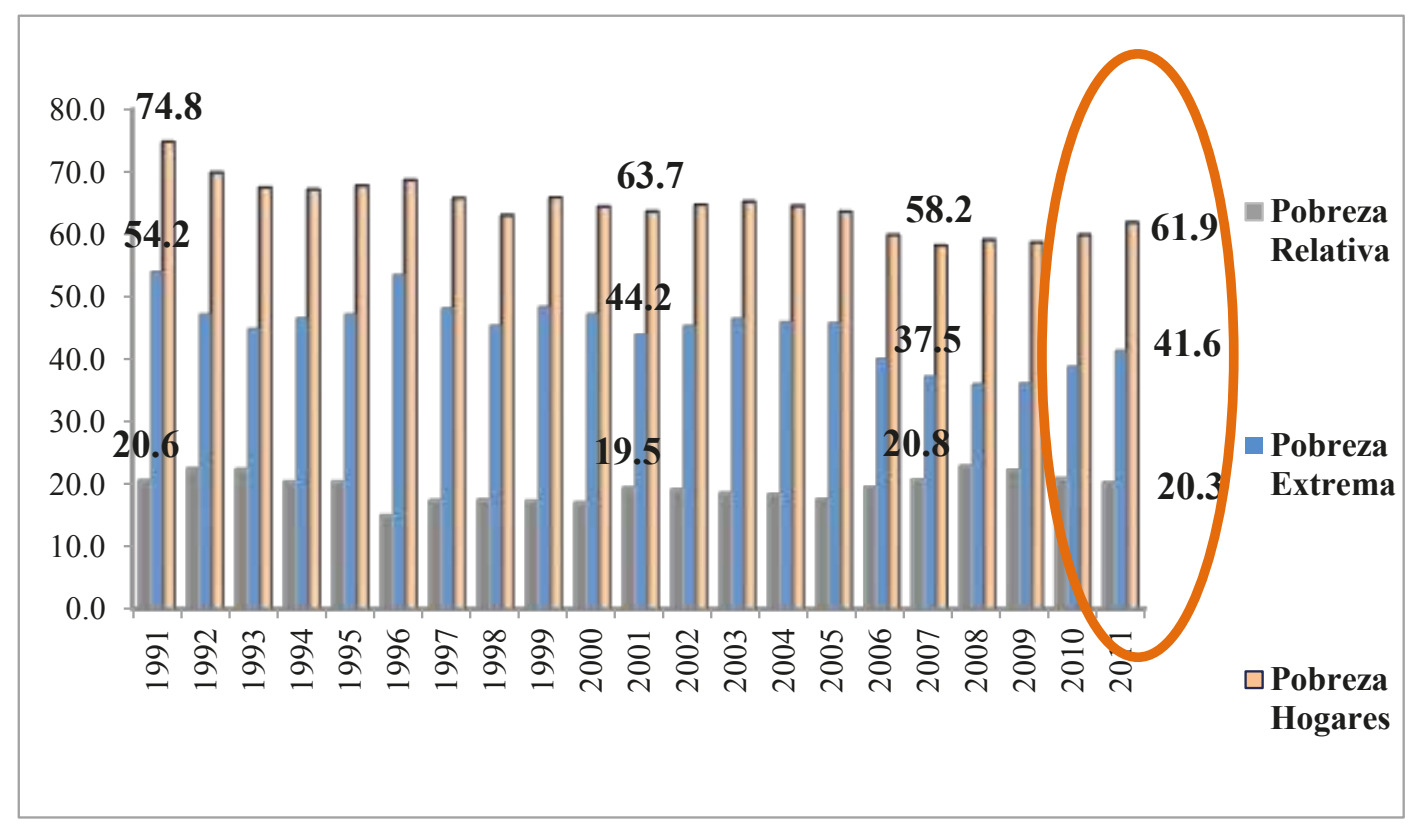

Fuente: Elaboración propia con base a la Encuesta de Hogares de Propósitos Múltiples (EPHPM).

\section{IV.1.2.-Pobreza por áreas Urbana y Rural}

Si se observa la figura No. 2 en el período 2002-2011, al final de ese período los hogares pobres disminuyo 2.0 puntos porcentuales, lo que refleja los esfuerzos gubernamentales de bajar los niveles de pobreza; sin embargo, al analizar los contextos urbanos y rurales se pueden observar algunos aspectos importantes, en el caso de los hogares urbanos pobres hubo una disminución de $6.3 \%$, lo que ha implicado que los esfuerzos aún focalizados en áreas urbanas principales como Tegucigalpa y San Pedro Sula no han sido suficientes para sacarlos de la pobreza, los pobres no disminuyeron, siguen ahí, y adicionalmente los pobres recientes se han incrementado (Ver figura No.2). 
En el caso de los hogares pobres de las áreas rurales, la tendencia indica que en el período hubo un aumento de los pobres en $2.3 \%$ al final de ese mismo período, lo que refleja que la política para combatir la pobreza no está llegando a las áreas rurales. Hay que destacar que entre el 2008-2009, se observa una baja generalizada en cada una de las áreas. Aunque la pobreza es más grave la zona rural con un $65.2 \%$, también en el área urbana alcanza a más de la mitad de los hogares con un $58.5 \%$.

Figura No. 2 Honduras: Hogares que viven en pobreza, según áreas de residencia urbano-rural período $2002-2011$

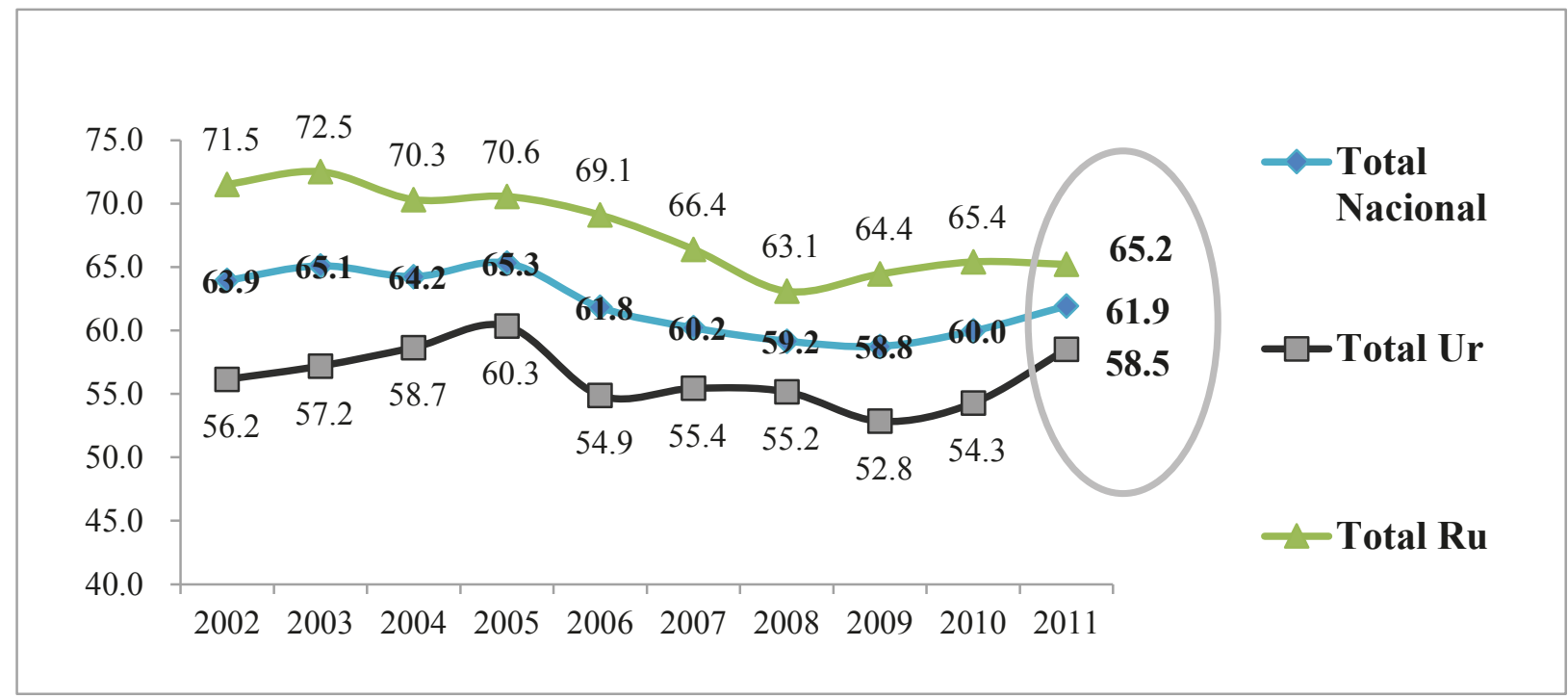

Fuente: Elaboración propia con base a la Encuesta de Hogares de Propósitos Múltiples (EPHPM).

\section{IV.1.3.-Ingreso per cápita a nivel nacional, urbano-rural y distribución de los ingresos 2001-2011}

En la figura No. 3 en el período 2001-2011 los ingresos per cápita a nivel nacional obtuvieron una tasa de crecimiento de un 8.6 \%, debido a la actividad económica del país; no obstante, al comparar área urbana y rural se observa una brecha entre el ingreso per cápita, en la área urbana fue superior al rural a inicio de la década en proporción de 2.5 veces, para el 2011 la brecha urbano-rural se dio en proporción 1.9 veces; lo que significa que el ingreso per cápita en el área rural ha mostrado una ritmo mayor de crecimiento con una tasa de un $10.9 \%$ en relación al ingreso per cápita urbano que tuvo un rimo de crecimiento de $7.8 \%$.

\section{IV.1.4.-La canasta básica}

Referente a la canasta básica se observa una brecha en el período 2001-2011 de forma estable para los años 2001-2006, a partir de ese año ha mostrado un crecimiento marcado; mostrando tasas de crecimiento del período de 7.1 puntos porcentuales en la zona urbana y de 6.9 puntos porcentuales en la zona rural, esto implica que la canasta básica ha mostrado un mayor incremento en la zona urbana que la rural, indicando que el costo de la vida es más costoso en las zonas urbanas (Ver Figura No. 3).

Por otra parte, al comparar los ingresos per cápita por urbano-rural con respecto a la canasta básica por urbano-rural, el análisis muestra que los ingresos per cápita de la zona urbana están en mejor posición, que los ingresos per cápita de la zona rural, lo cual genera mayor calidad de vida a este sector 
de la población, esta condición provocada por el crecimiento de la actividad económica y que gran parte del gasto corriente del Gobierno los perciben pobladores de la zona urbano. Adicionalmente se observa que a medida que ha incrementado el ingreso per cápita, la canasta básica ha mostrado en similar dinamismo.

Figura No. 3 Honduras: Ingreso per cápita-canasta básica urbano-rural período 2001-2011

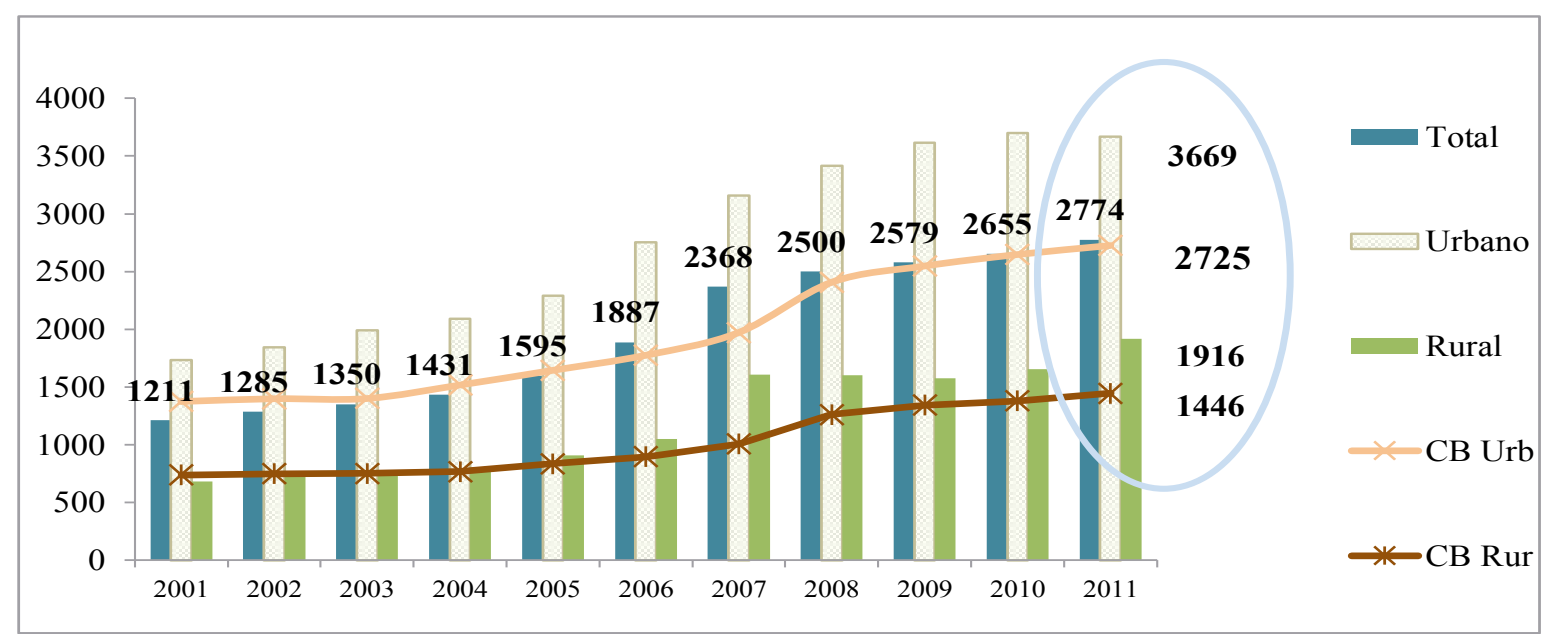

Fuente: Elaboración propia con base a la Encuesta de Hogares de Propósitos Múltiples (EPHPM)

\section{IV.1.5.-Evolución del coeficiente de Gini}

La Figura No .4 muestra el coeficiente de Gini calculados para Honduras, se observó una disminución leve de un 0.564 para el 2001 y de 0.525, 2009 como el punto más bajo en todo el período. En los siguientes años el 2010 y el 2011 mostró una tendencia creciente del coeficiente de Gini.

Importante destacar de la Figura No. 4 la tendencia del coeficiente de Gini, luego de un largo período de una tendencia ascendente marcada, mostro una leve disminución en los años 2008 y 2009, para luego seguir su tendencia al ascenso, lo que implica la inequidad de la distribución de los ingresos en Honduras seguirá siendo alta, en base a los criterios establecidos.

Figura No. 4 Honduras: Coeficiente de Gini en los períodos 2001-2011

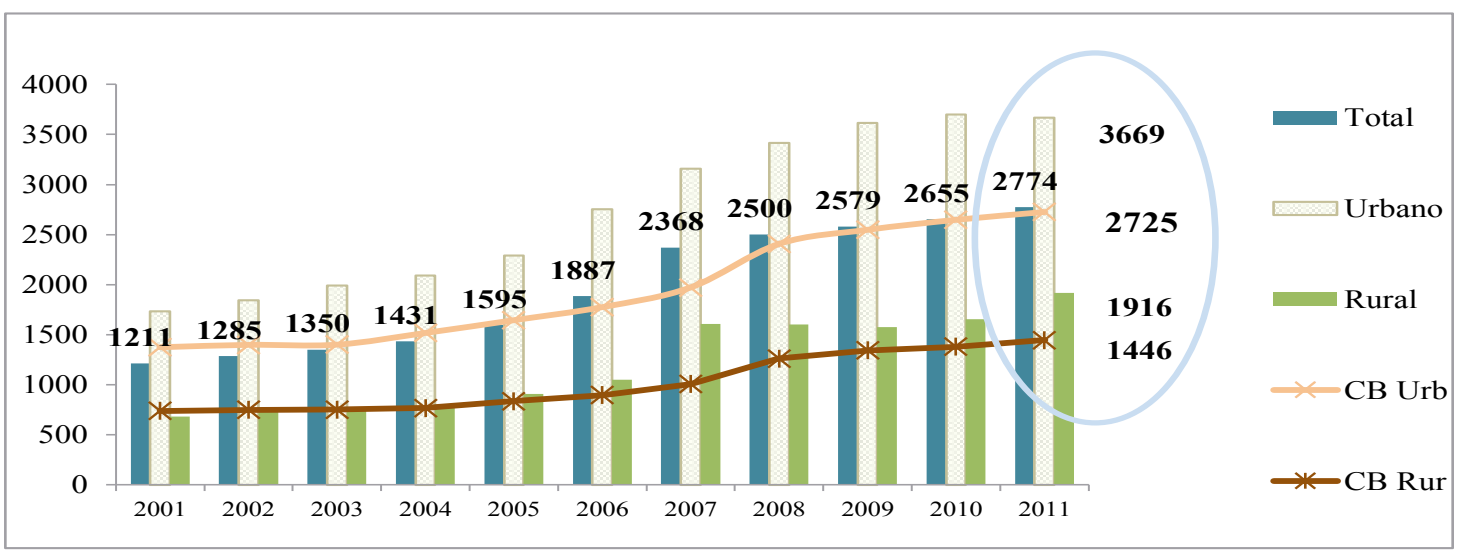

Fuente: Elaboración propia con base a la Encuesta de Hogares de Propósitos Múltiples (EPHPM). 


\section{IV.2.-Caracterización del Mercado Laboral}

\section{V.2.1.-Población Económicamente Activa/Tasa de Participación Laboral}

La población económicamente activa ${ }^{3}$ (PEA) con respecto a la población total, en el período del 2001 al 2012 ha tenido un importante incremento que pasó del 38.5\% al 40.5 respectivamente; es decir, que cada año se insertan más personas al mercado laboral ya sea como ocupados o buscando trabajo. A la vez, hay que resaltar que la PEA del área rural con respecto a su población total, es menor. Para el 2012 la PEA rural fue de 39.3\% y la PEA urbana fue de 42.0\% (Ver Figura No. 5).

Otro aspecto importante cuando analizamos la PEA por sexo es que el hombre tiene mayor participación que las mujeres, para el 2012 había alrededor de 2.19 millones de hombres económicamente activos y aproximadamente 1.16 millones de mujeres activos. Hay que tomar en cuenta que para 2012 había un 51\% de mujeres y un $49 \%$ de hombres a nivel nacional, sin embargo, hay una gran cantidad de mujeres que están insertas en actividades no remuneradas, como ser los cuidados de los hijos, los quehaceres del hogar, trabajador familiar no remunerado entre otros (Ver Figura No. 6).

Figura No. 5. Honduras: Población económicamente activa total nacional según área geográfica

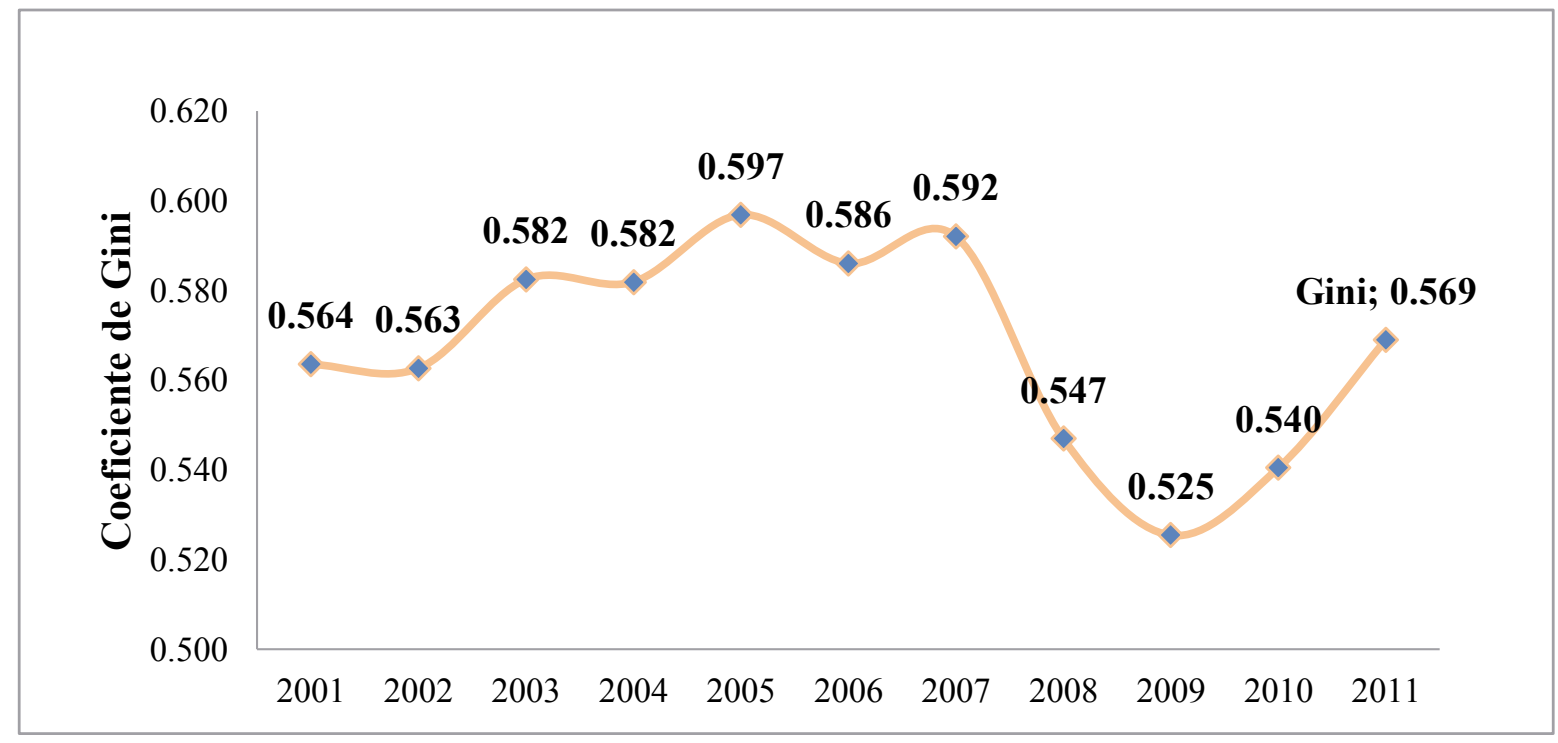

Fuente: Elaborado sobre los datos de la EPHPM de mayo 2001-2012

La tasa de participación ${ }^{4}$ en el mercado laboral en 2001 y 2012 fue de $53 \%$ a $51 \%$ respectivamente, disminuyendo casi 2 puntos porcentuales; ha sido un indicador con muchas fluctuaciones debido a que es muy sensible al desempleo. Es importante mencionar que las tasas de participación que tienen los hombres en el mercado laboral siempre han sido mayores que las mujeres, presentando grandes diferencias. Para 2012 la TP de los hombres era 69\% y de las mujeres un 34\%, de participación. 
Figura No. 6 Honduras: Tasa de Participación laboral, según área geográfica y nivel nacional

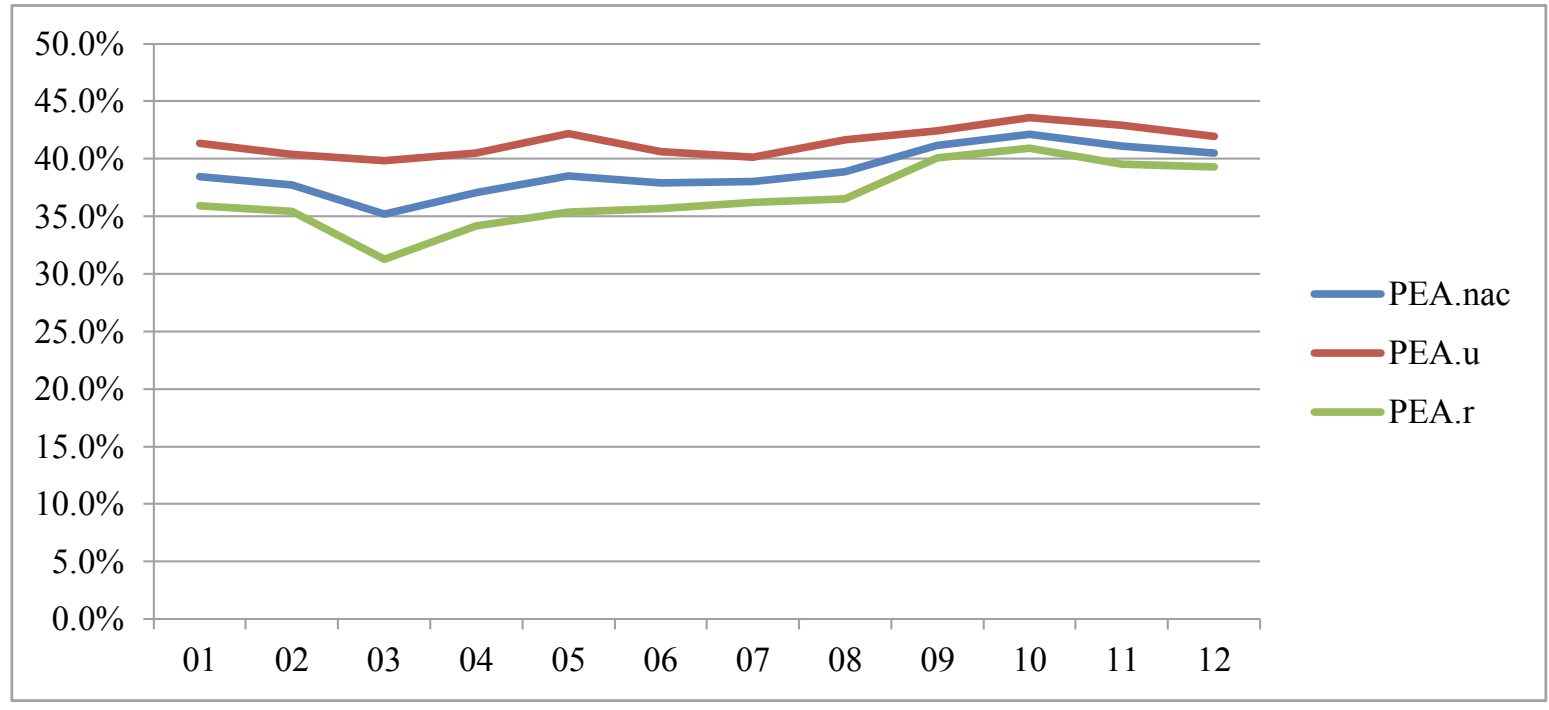

Fuente: Elaborado sobre los datos de la EPHPM de mayo 2001-2012

\section{V.2.2.-Actividad Económica de los Ocupados}

Respecto a los ocupados en 2001 la población ocupada alcanzo alrededor de 2.3 millones y en 2012 teniendo un alto incremento en valores absolutos. Para 2012 la población ocupada representó el $49 \%$ con respecto a la población en edad de trabajar, la población desocupada representó un $2 \%$ y la población inactiva el 49\%. Dentro de la población ocupada se encontró que un $46 \%$ de la población depende de un salario para poder suplir sus necesidades económicas, de alimentación, de salud y otros. Siendo el sector privado el que más empleo genera 33\% y el sector público genera un $7 \%$.

Las actividades económicas de mayor relevancia son: i.- La agricultura donde labora alrededor del $38 \%$ de la población ocupada, ii.- El comercio que agrupa casi el 22\% de dicha población y iii.- Los servicios que concentra $14 \%$ de los ocupados.

\section{V.2.3.- Categoría Ocupacional}

La participación según categorías ocupacionales tiene la misma tendencia en el periodo 2001-2012, específicamente para el 2012 estas categorías representaban de la población ocupada: i.- El 43\% de los trabajadores por cuenta propia, siendo esta categoría que esta categoría es un reflejo de las bajas condiciones socio-económicas de la población, ya que concentra el empleo informal de la economía, es decir que esta población no está integrada a los programas de previsión social ni a la protección de las leyes laborales; las ocupaciones como vendedores ambulantes, lustrabotas, pepenadores de café, ayudantes de ganadero y la agricultura, motoristas, fleteros, reparadores de celulares, cargadores de bultos, chatarreros entre otras ${ }^{5}$ (Ver Tabla No. 1). 
Tabla No. 1

Honduras: Ocupadas a nivel nacional

Clasificación $\quad$ Total, Nacional $\%$

Ocupados

Asalariados

Publico

Privado

Domestico

Cuenta Propia

Trab. Fam. No Remun.
3243,877

100

1351,171

41.7

211,891

15.7

$1071,616 \quad 79.3$

67,664

5

$1404,345 \quad 43.3$

432,868

Fuente: Elaboración sobre la información de EPHPM, 2012.

\section{V.2.4.-Desempleo}

Para Honduras uno de los mayores problemas es el desempleo ${ }^{6}$, que ha tenido casi el mismo comportamiento del 2001 al 2012, ya que la tasa promedio de desempleo para 2001 fue de $4.2 \%$ y para 2012 un 3.6\%, es decir que abarco a 120,811 trabajadores este último año. En relación a las brechas de desigualdades, para el 2012 había 62,754 hombres desocupados y 58,057 mujeres desempleadas representando la tasa de desempleo abierto (TDA) para los hombres un 2.9\% y para las mujeres un 5.0\%, teniendo las mujeres mayores problemas de inserción al mercado de trabajo (Ver Gráfico No. 7). El mayor problema se refleja en el subempleo o aquellos trabajadores que trabajan menos horas de lo que quisieran trabajar y ganan menos de los salarios regulados por el estado ${ }^{7}$.

Para el 2012 el subempleo visible ${ }^{8}$ alcanzo el 10.5\%, es decir, alrededor de 339 mil personas; el mayor problema se refleja en el subempleo invisible 9 que alcanzo el 43.6\%; es decir, el 1.4 millones de trabajadores ubicados en este tipo de empleo, lo que constituye una problemática grave para el mercado laboral en Honduras. 
Figura No. 7 Honduras: Tasa de desempleo abierto 2001 a 2012

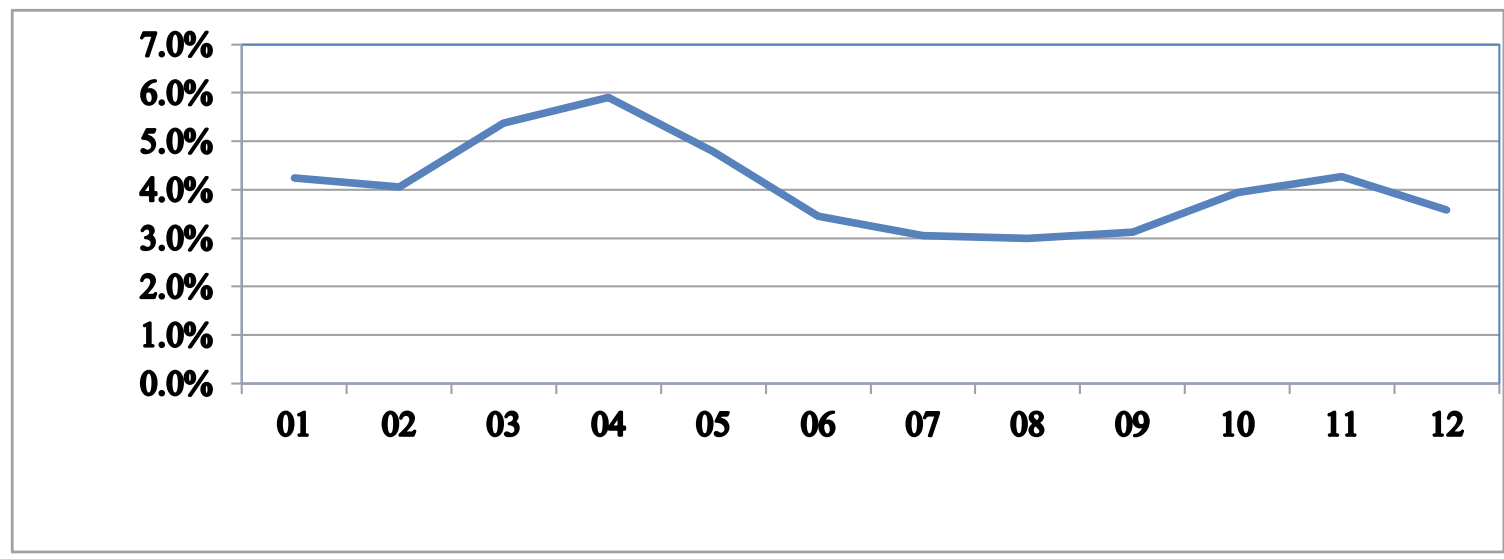

Fuente: Elaborado sobre los datos de la EPHPM de mayo 2001-2012

\section{V.3.- Caracterización del Gasto Social y de la Protección Social en Honduras}

El gasto social en su sentido más generalizado se refiere a aquellos recursos que provienen del estado principalmente para ofrecer bienes y servicios a diferentes sectores de la sociedad en las áreas de educación, salud, vivienda o previsión social, lo que se le denomina (GPS) por medio de pagos de transferencias. Los recursos destinados para el financiamiento de planes, programas y proyectos, de manera que estos producen un impacto favorable a un problema social específico de una fuente de financiamiento ya sea pública, privado, donaciones o de otras fuentes externas.

Por otro lado, la protección social que también puede entenderse como seguro social o previsión social se refiere a que el Estado principalmente ofrece un nivel de cobertura de las necesidades sociales (la salud, la vejez, invalidez y/o discapacidades laborales y las jubilaciones) supuestamente a todos los sectores de la población, pero de manera especial a aquellos sectores que tienen privaciones económicas y sociales idealmente. Desde este punto de vista, la protección social no solo debe ser parte central de las políticas sociales, debe asegurar un nivel básico de bienestar económico y social para todos los miembros de la sociedad.

Por otro lado, en cuanto a reformas al marco institucional de la protección social, Honduras no ha impulsado ninguna reforma estructural a su sistema de pensiones en las últimas dos décadas (Mesa-Lago, 2008), lo que refleja los presupuestos en los diferentes programas y proyectos sociales. Los grupos que están fuera de este contexto de protección social son los pobres, desempleados, sub-empleados, trabajadores informales y los que viven en zonas rurales alejados de todos los servicios sociales que son más bien urbanos.

Por otro lado, en el país han existido programas y proyectos sociales de naturaleza contributiva y no contributiva, que se han generado en diferentes momentos, con diferentes objetivos y no han sido organizados e integrados necesariamente en un sistema como tal. Sin dejar de lado, que la protección social en el país se ha dado por momentos históricos de su desarrollo económico-social, mediados por factores de orden políticos, organizacionales propios del país (Bertranou, 2005). En este contexto, Honduras, así como el resto de los países latinoamericanos 2 de cada 3 hondureños no tienen cobertura básica y de calidad de los riesgos sociales: i.- Enfermedad, ii.- Perdida de ingresos (desempleo, sobrevivencia, enfermedad, invalidez o vejez). 


\section{V.3.1.- Gasto público, gasto social relativo al PIB y gasto per cápita}

En términos generales el gasto social en Honduras históricamente ha estado muy por debajo del promedio en Latinoamérica, lo que implica que el impacto de los actuales programas y proyectos no están teniendo la cobertura, la calidad y el impacto de los sectores en mayores desventajas sociales. A pesar de esta situación, se han hecho esfuerzos para mejorar la cobertura con un criterio pro-pobre, lo que implica llevar los servicios sociales para el mejoramiento de las condiciones de vida a aquellos sectores de la sociedad más pobres.

Para entender cómo ha sido el comportamiento de la asistencia y la seguridad social en el país, es importante contextualizarlos dentro del ámbito del gasto social, o sea aquellos recursos del PIB que el Estado asigna para satisfacer estas necesidades prioritarias de la población frente a medidas estructurales de orden macroeconómico.

Siguiendo el gasto público social como porcentaje del PIB en Honduras, se observó que creció 7 puntos porcentuales en el período de 1998-2010, pasando del 5.4\% en 1998 al 12\% en el 2010.

Asimismo, el gasto social per cápita casi se triplicó durante ese período, pasando de \$68.00 a \$183.00 dólares; lo cual refleja una mejoría relativa dentro del contexto general y muestra un ascenso sostenido en el tiempo (Ver Gráfico No. 8). Asimismo, la participación del gasto social dentro del gasto público total aumento, pasó del 37\% en 1998 a 52\% en el 2010.

Por otro lado, el gasto social en seguridad social (GPSS) como porcentaje del PIB pasó de $0.4 \%$ en 1998 a $0.6 \%$ en 2010, sin embargo, llego a alcanzar niveles en ascenso en el 2008 de 0.8 , a partir del cual ha venido bajando rápidamente, lo que refleja que se dejaron de atender programas y proyectos en materia de seguridad social.

Esto no es más que el área social no ha sido una prioridad para los diferentes gobiernos, el gasto social ha quedado postergado y está en los últimos lugares de toda la región latinoamericana.

Figura No. 8 Honduras: Gasto Público Social Per Cápita (en \$ 2005), Gasto Público Social Relativo al PIB Y Gasto Público Total, 1998-2010 (En porcentajes y dólares)

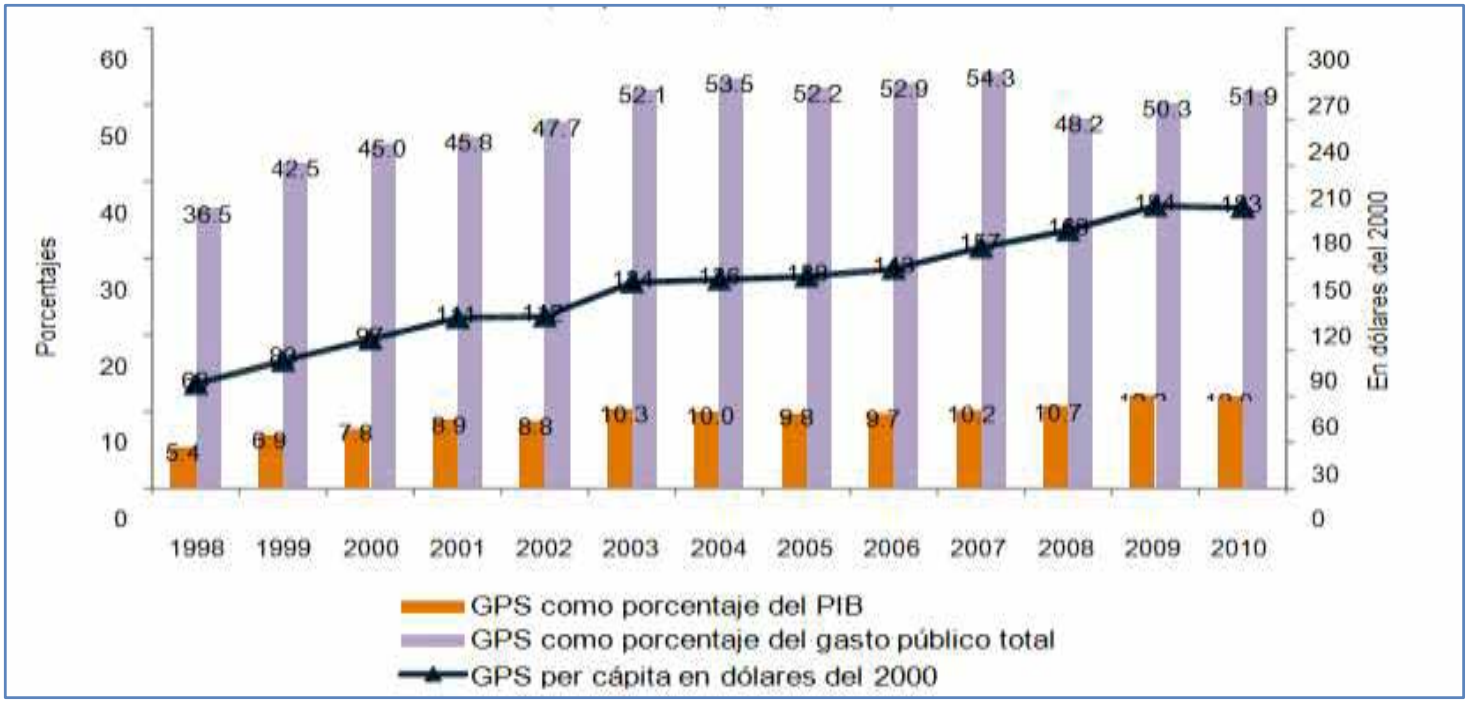

Fuente: Comisión Económica para América Latina y el Caribe (CEPAL) 
Viendo el gasto social per cápita pasó de $\$ 5.00$ per cápita a $\$ 10.00$ per cápita, lo que se ve una leve mejoría, sin embargo, no es suficiente para invertir a nivel per cápita para asegurar la equidad de los recursos sociales, dejando atrás a muchos segmentos de la población sin tener acceso a ellos. (Ver figura No. 9.)

Figura No. 9 Honduras: Gasto Social en Seguridad Social (GPSS) Per Cápita (En dólares 2005) Y Como Porcentaje Del PIB (En Dólares 2005)

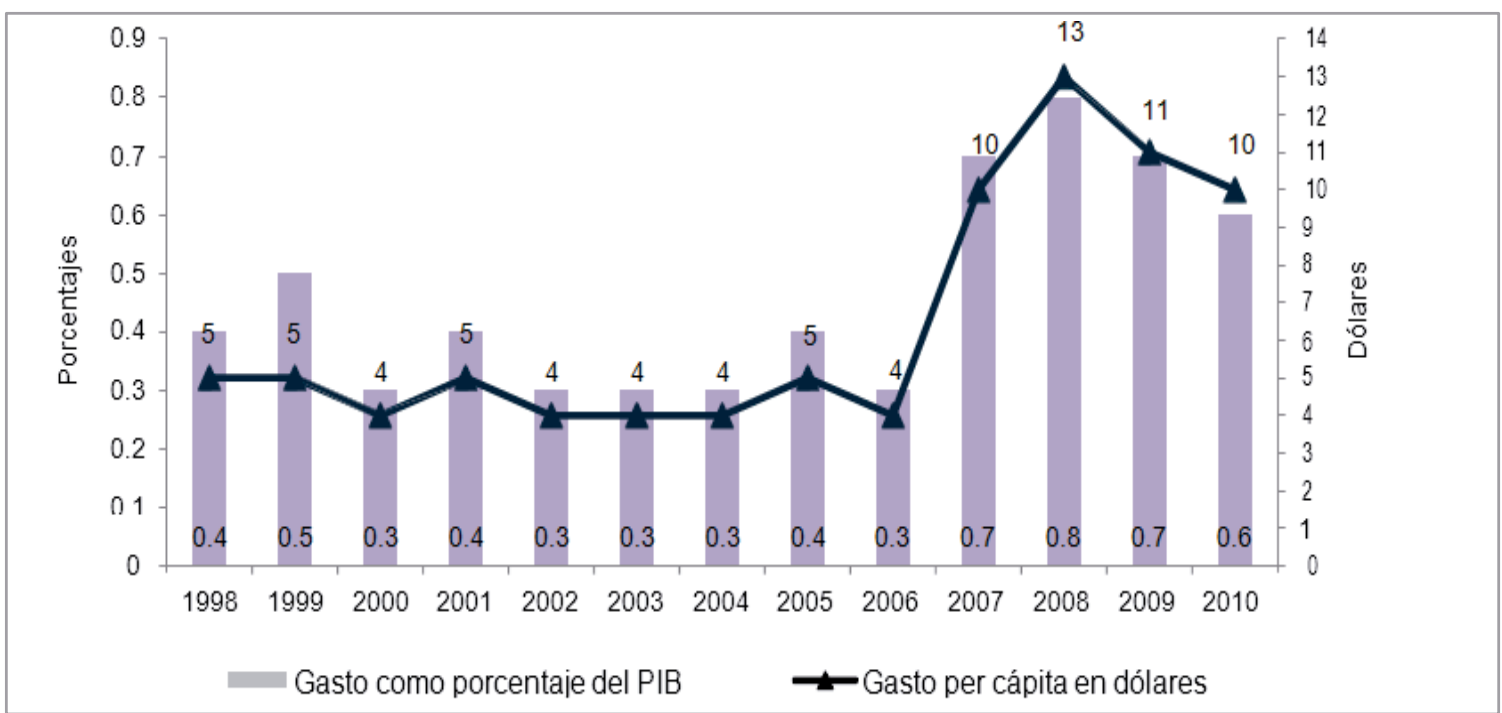

Fuente: Comisión Económica para América Latina y el Caribe (CEPAL), Base de datos gasto social.

\section{V.3.2.- Gasto público social sectorial}

Si se observan las distribuciones porcentuales del gasto público social sectorial con respecto al PIB, se puede apreciar en el periodo de referencia 1998-2010 que el sector en el cual se ha enfocado el gasto social público es el de educación, alcanzando las $2 / 3$ del gasto total destinado en el período, en salud superando $1 / 3$ del gasto total y apenas hubo crecimiento en el sector de seguridad social. Como se puede apreciar en la figura No. 3.

El gasto en educación en relación al PIB en el período de 1998-2010 se duplicó con holgura, pasando del 3,2\% en 1998 al 7,7\% en el 2010, siendo el sector social que recibió la mayor parte del gasto público social, seguido por el de la salud. El gasto en salud en relación al PIB paso de $1.8 \%$ en 1998 a 3.5\% del 2010. Por otro lado, el gasto en seguridad social en relación al PIB apenas cambio en dos décimas, pasó de $0.4 \%$ en 1998 a $0.6 \%$ en el 2010 , siendo muy residual este aumento y en el que menos se ha invertido. En el período 2003-2007 el gasto en seguridad social permaneció prácticamente igual, apenas por debajo del $1 \%$ del PIB. (Ver figura No. 10). 
Figura No. 10 Honduras: Gasto Público Social Por Sector Como Porcentaje Del PIB, 1998-2010

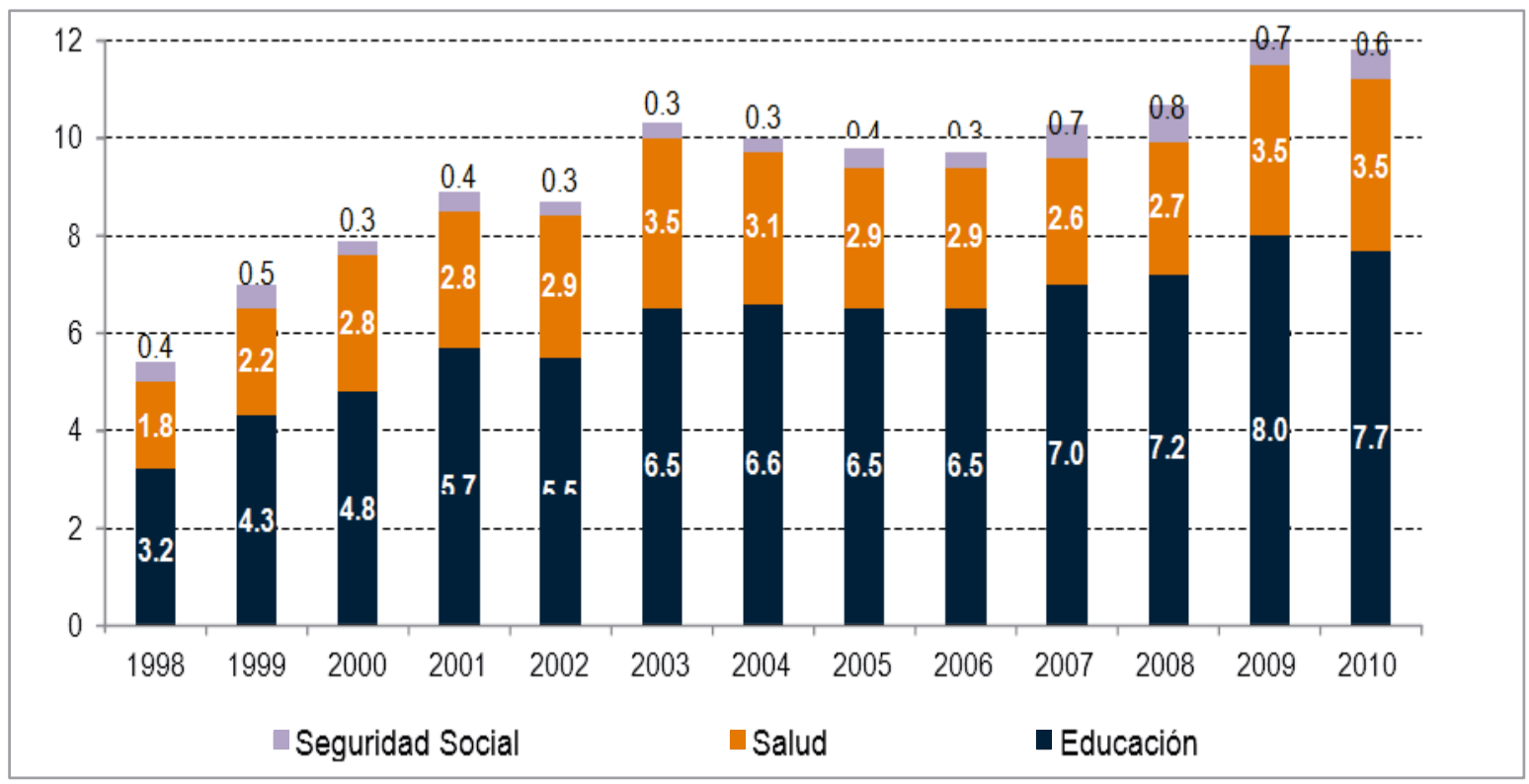

Fuente: Comisión Económica para América Latina y el Caribe (CEPAL), Base de datos gasto social.

\section{V.3.3.- Gasto en Salud}

El sector salud no es uno de los más privilegiados en cuanto a gasto, según Badillo et al. (2009) el sistema de salud recibe recursos públicos insuficientes, provocando que la mayor parte del financiamiento se genere por vía privada y familiar, lo cual refuerza la inequidad. Obviamente esto refleja que el sector ha tenido fuertes inconsistencia en la entrega de servicios de salud a la población, que se van haciendo menos eficientes en la medida de los cambios demográficos y epidemiológicos.

Asimismo, como el cambio del cuadro de enfermedades del país ha pasado de la erradicación de enfermedades como la polio, sarampión y rubeola a enfermedades infecciosas intestinales y las respiratorias agudas y desnutrición en menores de 5 años; en adultos, el mejoramiento de la calidad de vida se refleja en mejores condiciones de salud y aumento de la esperanza de vida al nacer, sin embargo, la incidencia de enfermedades graves como la malaria, la tuberculosis y el cólera siguen afectando a la población. La incidencia del dengue clásico y hemorrágico ha aumentado, asimismo, como las infecciones gastrointestinales y el mal de chagas.

Por otro lado, de las causas de muerte en Honduras se encuentran las enfermedades respiratorias, infecciones no-respiratorias y padecimientos cardiovasculares, asimismo, como el aumento de algunos tipos de cáncer que podrían ser prevenibles si se diera un diagnóstico temprano y oportuno. La mortalidad por causas violentas es una de las más importantes, sobre todo en los grupos intermedios de la población.

Otro aspecto importante a considerar es que las conformaciones de los grupos de edad van modificándose y de igual manera sus necesidades de servicios de salud han cambiado. Originando tres aspectos de la salud: i.- Aun se siguen tratando enfermedades de origen trasmisible en el país, ii.- Se están originando nuevas enfermedades originadas por falta de previsión sanitaria, y iii.- La creciente demanda de servicios de salud. 
En este contexto, en la Figura No. 11 se puede apreciar la tendencia del gasto público en salud como porcentaje del gasto público total pasó del 32.5\% en 1998 a 28.7\%, lo que refleja más bien una contracción de 3.8 puntos porcentuales, en detrimento del sector. Sin embargo, el gasto público a nivel per cápita en salud pasó de \$22.00 en 1998 a \$52.00 en el 2010, teniéndose una mejoría considerable a este nivel.

\section{V.3.4.- Gasto en Educación}

La educación juega un papel bien importante en el aumento de la productividad. De hecho, es el sector que más ha recibido presupuesto en los últimos años, su importancia radica enque si se logra un más alto nivel educativo la población puede hacerles frente a las situaciones de pobreza y sobrevivencia; una población de estudiantes que alcancen como mínimo su nivel educativo tiene mejores perspectivas de trabajo para lograr mejores ventajas comparativas en el mercado de trabajo frente al riesgo de la pobreza.

Figura No. 11 Honduras: Gasto público y privado en salud, 1998-2010

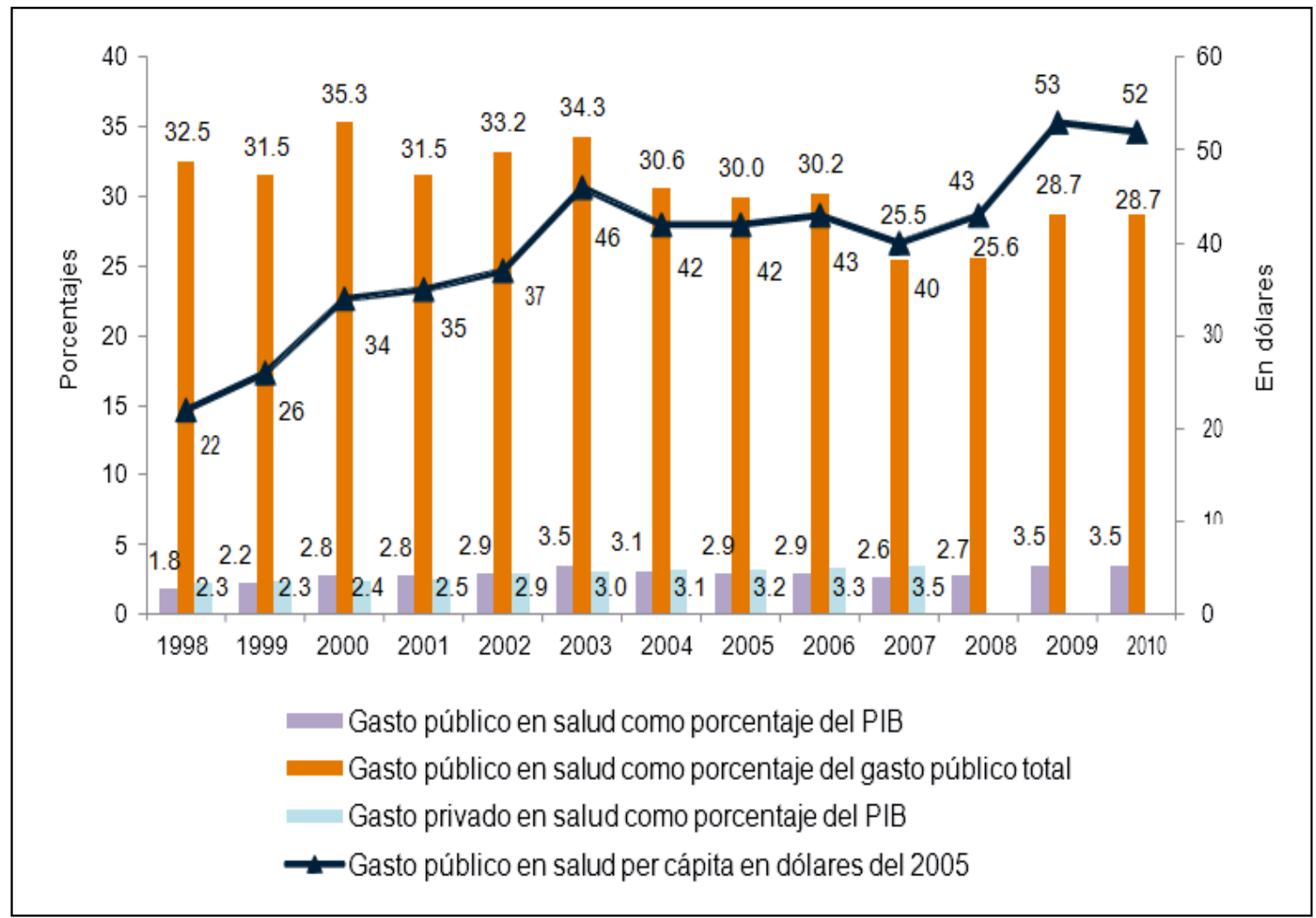

Fuente: Comisión Económica para América Latina y el Caribe (CEPAL) y Organización Mundial de la Salud (OMS).

Solo siguiendo el comportamiento del gasto en educación, se puede apreciar que la tendencia del gasto público en educación como porcentaje del gasto público total ha oscilado entre el $60 \%-63.5 \%$ en el período de referencia (Ver Figura No. 12), para 1998 al 2010 respectivamente, teniendo su porcentaje más alto de $68 \%$ en el 2007; lo que refleja más bien se ha mantenido el nivel del gasto en este sector. Sin embargo, el gasto público a nivel per cápita en educación pasó de $\$ 41.00$ en 1998 a $\$ 175.00$ en el 2010, un aumento cuádruple en el período, siendo el sector más alto en cuanto gasto per cápita. 
Figura No. 12 Honduras: Gasto en Educación Per Cápita (En Dólares)

como Porcentaje del PIB y Como Porcentaje del Gasto Público Total

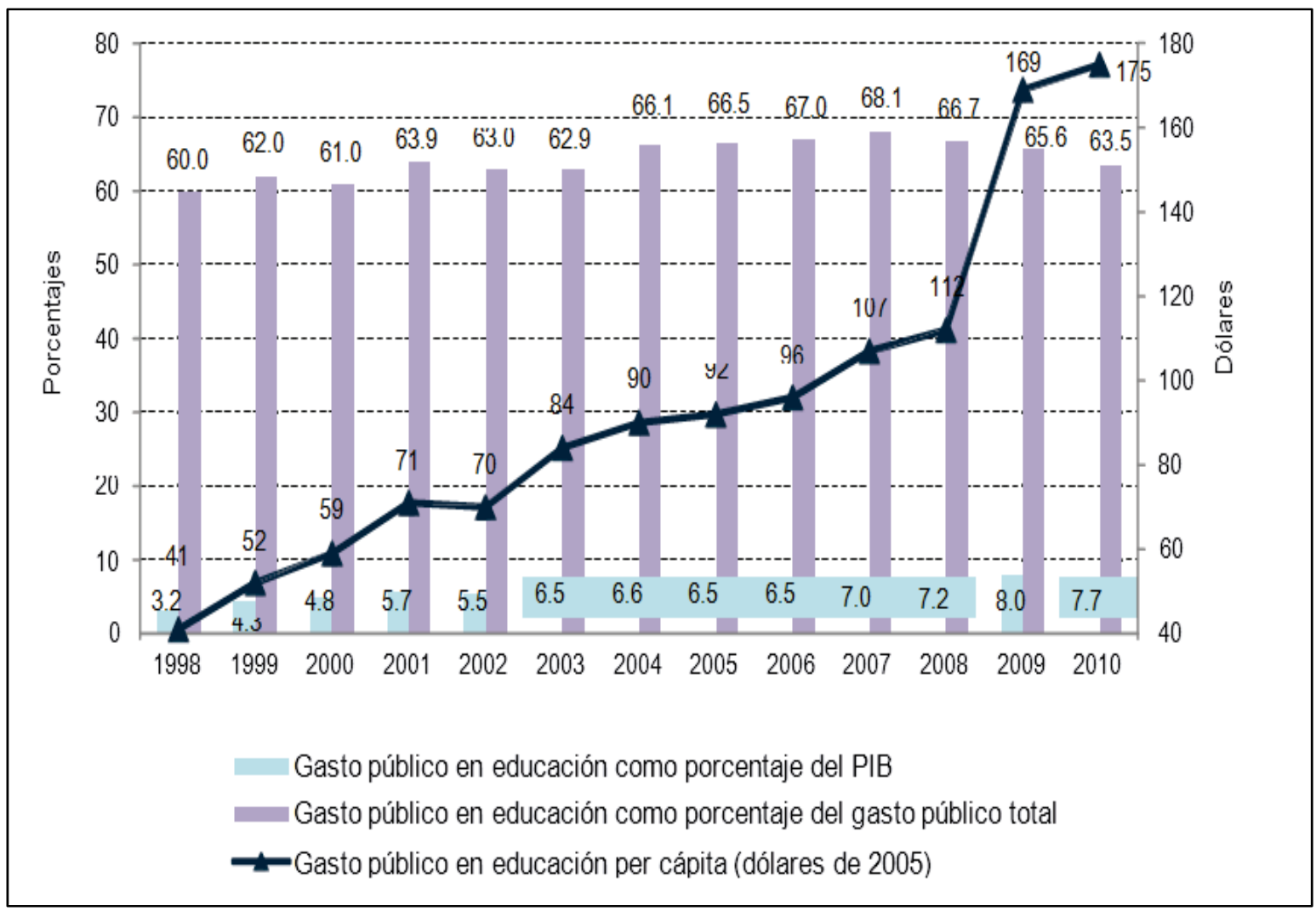

Fuente: Comisión Económica para América Latina y el Caribe (CEPAL) y Sistema de la Integración Centroamericana (SICA).

\section{V.3.5.- Gasto social en seguridad social y financiamiento del sistema}

Finalmente, el gasto en seguridad social es el que menos ha recibido financiamiento ya sea del Estado o de otras fuentes de financiamiento. Cichon et al. (2004) mencionan que el gasto en protección social generalmente está dado por el producto entre el número de beneficiarios y el monto de los beneficios. Para tener una noción de su magnitud de trabajadores en la economía y el producto por trabajador. Se puede decir que el gasto en protección social está determinado por tres grandes factores: i.- demográficos, ii.- económicos, iii.- y de gobernabilidad.

El entorno demográfico en el que un sistema de protección social opera afecta principalmente el número potencial de beneficiarios (niños, jubilados) y el número potencial de trabajadores. El entorno económico, por su parte, afecta el número de beneficiarios (por ejemplo: desempleados), el monto de los beneficiarios y le producto bruto por trabajador. Y en los aspectos de la gobernabilidad tienen impacto en los beneficiarios que se brindan y las condiciones de elegibilidad.

De manera que, viendo estos entornos, se puede decir que el gasto en protección social es pro-cíclico, que se contrae en tiempos de crisis económica y se expande en condiciones de mejoría de la economía, lo que ha provocado que los programas y proyectos orientados a la protección social se ven afectados por esas eventualidades económicas. 
El gasto en seguridad social en el período 1998-2006 fue extremadamente bajo o inferior al 1\% del PIB; sin embargo, el gasto per cápita se duplicó aumentando de \$5.00 dólares en 1998 a \$10.00 dólares en 2010. La evolución del gasto en el régimen general de pensiones como porcentaje del PIB, ha permanecido muy bajo, en el 2007 era de solo el 0,1\% del PIB.

\section{VI.- CONCLUSIONES}

1.- El contexto general de la protección social en Honduras está matizado de aspectos sociales y económicos, no se puede extraer de toda una realidad y sobre todo de aquellos sectores de la población que no disfrutan de un nivel básico de protección social porque son grupos excluidos de toda acción gubernamental ya que no están como población objetivo de los programas y proyecto sociales.

2.- Los grupos de población que están fuera de este contexto de protección social son los pobres, desempleados, sub-empleados, trabajadores informales y los que viven en zonas rurales alejados de todos los servicios sociales que son más bien urbanos. En Honduras, así como, en el resto de los países latinoamericanos 2 de cada 3 personas no tienen cobertura básica y de calidad de los riesgos sociales: Enfermedad, pérdida de ingresos, desempleo, sobrevivencia, enfermedad, invalidez o vejez.

3.- Por otro lado, los niveles de pobreza en el país permanecen altos, a pesar de los esfuerzos sistemáticos que se han realizado durante décadas, para el 2011 la pobreza había alcanzado $1,718.338$ hogares, que cubre el $61.9 \%$, el $20.3 \%$ de estos hogares son pobres relativos y $41.6 \%$ son pobres extremos. La pobreza rural es mayor que la pobreza urbana.

4.- La PEA ha llegado al 2012 con un $40.5 \%$, es decir, que cada año se insertan más personas al mercado laboral. A la vez, hay que resaltar que la PEA rural es menor que la del área urbana. Para el 2012 la PEA rural fue de 39.3\% y la PEA urbana fue de $42.0 \%$. Otro aspecto importante cuando analizamos la PEA por sexo es que el hombre tiene mayor participación que las mujeres, para el 2012 había alrededor de 2.19 millones de hombres económicamente activos y aproximadamente 1.16 millones de mujeres activos.

5.- En cuando al gasto social si se observan las distribuciones porcentuales del gasto público social sectorial con respecto al PIB, puede apreciar que el sector en el cual se ha enfocado el gasto social público es el de educación, alcanzando las 2/3 del gasto total destinado en el período, en salud superando $1 / 3$ del gasto total y apenas hubo crecimiento en el sector de seguridad social.

6.- El gasto en educación en relación al PIB en el período de 1998-2010 se duplicó con holgura, pasó de 3,2\% en 1998 al 7,7\% en el 2010, siendo el sector social que recibió la mayor parte del gasto público social. El gasto en salud en relación al PIB paso de $1.8 \%$ en 1998 a 3.5\% del 2010. Por otro lado, el gasto en seguridad social en relación al PIB apenas cambio en dos décimas, pasó de $0.4 \%$ en 1998 a $0.6 \%$ en el 2010, siendo muy residual este aumento y en el que menos se ha invertido. En el período 2003-2007 el gasto en seguridad social permaneció prácticamente igual, apenas por debajo del 1\% del PIB. 


\section{REFERENCIAS BIBLIOGRÁFICAS}

Badillo, P., García, C., Castro, M. \& Menkos, J. (2009). Financiamiento de la protección social y pensiones de Honduras. En El financimiento de la protección social en países pobres y desiguales: Hacia la universalidad, con solidaridad y eficiencia de la protección social en los países pobres y desiguales (pp. 91-145). Serie seminarios y conferencias, división de desarrollo social CEPAL.

Bertranou, F. (2005) Envejecimiento de la población y los sistemas de protección social. En América Latina, consecuencias económicas y sociales del cambio en la estructura de edades. México: División de Población de las Naciones Unidas y Consejo Nacional de Población de México.

Busso, G. (2001). Vulnerabilidad social: nociones e implicancias de políticas para Latinoamérica a inicios del siglo XXI. Documento presentado en el Seminario Internacional "Las diferentes expresiones de la vulnerabilidad social en América Latina y el Caribe” (Santiago de Chile, 20 y 21 de junio), inédito. CEPAL. (2013). “Estudio Económico de América Latina y el Caribe,”. www. cepal.org/de.CELADE (2008). Tendencias demográficas y protección social en América Latina y el Caribe (29-40). Santiago de Chile: División de Población/Fondo de las Naciones Unidas.

Cichon, M., Wolfgangz, S., van de Meerendonk, A., Hagemejer, K., Bertranou, F. \& Plamondon, P. (2004). Financing social protection quantitative methods in social protection series, Geneva: OIT.

CNEG, (2010). "Resumen del contenido del decreto 286-2009 sobre la ley para el establecimiento de una visión de país y la adopción de un plan de nación para

Honduras,".www.sre.gob.hn/nation plan espanol.pdf

CONADEH. (2012). Informe anual del comisionado nacional de los derechos humanos sobre el estado general de los derechos humanos en honduras y el desempeño de sus funciones Cuevas, A. G., \& Kohn, A. G. (2010). Pobreza y vulnerabilidad social.

ERP, (2001). "Estrategia para la reducción de la pobreza,. www.fosdeh.com/archivos/documentos/...a...pobreza/erp completo.pdf

Feres, J. C. (1997). Notas sobre la medición de la pobreza según el método del ingreso. Revista de la CEPAL, 61, 119-133.

Feres, J. C., \& Mancero, X. (2001). Enfoques para la medición de la pobreza: breve revisión de la literatura. CEPAL.

Fondo Monetario Internacional. (2001). Manual de estadísticas de finanzas públicas (2da. ed.). Fondo Monetario Internacional.

INE. (2011). XLI Encuesta Permanente De Hogares De Propósitos Múltiples. Publicación, Instituto Nacional de Estadística de Honduras.

INE. (2010). XXXIX Encuesta Permanente De Hogares De Propósitos Múltiples.

Publicación, Instituto Nacional de Estadística de Honduras. 
INE, Honduras. (2001-2012). Encuesta Permanente de Hogares de Propósitos Múltiples.

INE, Honduras. (2012). Encuesta Permanente de Hogares de Propósitos Múltiples.

INEI, (1998). "Encueta Nacional de Hogares Sobre Condiciones de Vida,".

www.inei.gob.pe/biblioineipub/bancopub/Est/Lib0073/cap0402.htm

Larrañaga, O. (2007). La medición de la pobreza en dimensiones distintas al ingreso. Naciones Unidas, CEPAL, División de Estadística y Proyecciones Económicas.

León, S. M. O. (2007). La Ley General de Desarrollo Social y la medición de la pobreza.

López de Mazier, A. (2002). El flagelo de la pobreza en Honduras y su impacto en la infancia, adolescencia y familia. Tegucigalpa: IEES-UNAH.

Martínez Franzoni, J. (2013). Sistemas de Protección Social en América Latina y el Caribe: Honduras. Santiago de Chile : CEPAL.

Martínez, R. \& Collinao, M. P. (2010), Gasto social: Modelo de medición y análisis para

América Latina y el Caribe Santiago de Chile, Publicaciones de las Naciones Unidas.

Mesa-Lago, C. (2008). Un reto de Iberoamérica en el siglo XXI: La extensión de la cobertura de la seguridad social. América Latina Hoy, (48), 67-81. http:// www.eclac.org/publicaciones/xml/4/36014/SSC_55_ProteccionSocial.pdf

Maestría En Demografía Social, UNAH. (2010). Transición Demográfica. Población y Desarrollo Argonautas y Caminantes , 6 (6), 38-39.

Ravallion, M. (1999). Las líneas de pobreza en la teoría y en la práctica. Taller Regional Mecovi, Buenos Aires.

Serrano, C. (2005). Claves de la política social para la pobreza. Manuscrito no publicado. 
Rodulio, P. 2011. Diagnóstico de las políticas de protección social. Comunicado de prensa, Tegucigalpa.

Sojo, A. (Editora). (2011) Hacia la universalidad, con solidaridad y eficiencia: El financiamiento de la protección social en países pobres y desiguales

Sojo, A. (Editora). (2011) Hacia la universalidad, con solidaridad y eficiencia: El financiamiento de la protección social en países pobres y desiguales. 